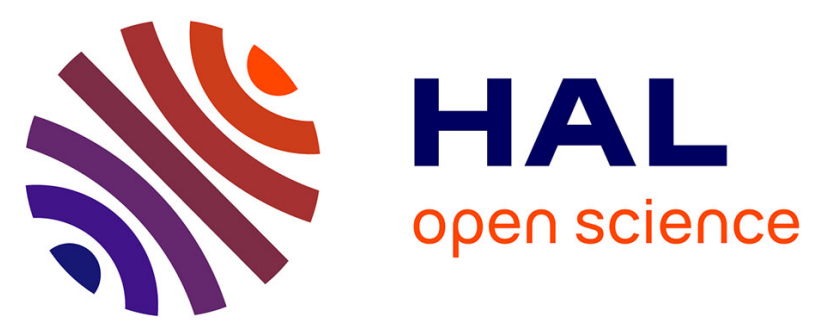

\title{
A comparative analysis of patch-leaving decision rules in a parasitoid family
}

\author{
Eric Wajnberg, Pierre-Alexis Gonsard, Elisabeth Tabone, Christine Curty, \\ Nathalie Lezcano, Stefano Colazza
}

\section{- To cite this version:}

Eric Wajnberg, Pierre-Alexis Gonsard, Elisabeth Tabone, Christine Curty, Nathalie Lezcano, et al.. A comparative analysis of patch-leaving decision rules in a parasitoid family. Journal of Animal Ecology, 2003, 72, pp.618-626. 10.1046/j.1365-2656.2003.00731.x . hal-02683401

\section{HAL Id: hal-02683401 https://hal.inrae.fr/hal-02683401}

Submitted on 1 Jun 2020

HAL is a multi-disciplinary open access archive for the deposit and dissemination of scientific research documents, whether they are published or not. The documents may come from teaching and research institutions in France or abroad, or from public or private research centers.
L'archive ouverte pluridisciplinaire HAL, est destinée au dépôt et à la diffusion de documents scientifiques de niveau recherche, publiés ou non, émanant des établissements d'enseignement et de recherche français ou étrangers, des laboratoires publics ou privés. 
Journal of Animal

Ecology 2003

72, $618-626$

\title{
A comparative analysis of patch-leaving decision rules in a parasitoid family
}

\author{
ERIC WAJNBERG*, PIERRE-ALEXIS GONSARD*ELISABETH TABONE*, \\ CHRISTINE CURTY*, NATHALIE LEZCANO* and STEFANO COLAZZA $\dagger$ \\ *INRA, 37 Boul. du Cap, 06600 Antibes, France; and $\uparrow$ S. En.Fi. Mo.Zo Department, University of Palermo, Viale delle \\ Scienze, 13-90128 Palermo, Italy
}

\begin{abstract}
Summary
1. The proximate behavioural rules adopted by parasitoid females to manage their foraging time on patches of hosts were studied, under standardized laboratory conditions, in different species (and populations) of the Trichogrammatidae (Hymenoptera) family. 2. Seventeen species/populations were compared and the behavioural mechanisms adopted by the females were identified by means of a Cox's proportional hazards model. 3. On average, females increased their patch-leaving tendency each time a healthy host was attacked and each time a parasitized host was rejected.

4. Strong variation was observed in these patch-leaving mechanisms among the different species.

5. Moreover, the interspecific variation in these two behavioural mechanisms showed a significant positive correlation, and this correlation remained significant when the phylogenetic relationship between the strains was controlled with the use of phylogenetic comparative methods.

6. The adaptive and evolutionary meanings of these results are probably related to the ecological features and distribution patterns of the hosts attacked by the species/populations compared.
\end{abstract}

Key-words: insect parasitoids, patch time allocation, proportional hazards model, Trichogrammatidae.

Journal of Animal Ecology (2003) 72, 618-626

\section{Introduction}

Most parasitoid species attack hosts that are distributed in discrete patches in the environment (Godfray 1994), and a large number of both experimental and theoretical works have tried to describe and understand the behaviour of female parasitoids exploiting such patchily distributed resources. From the seminal papers by Emlen (1966) and MacArthur \& Pianka (1966), the central question in such works is to understand how parasitoid females allocate their foraging time on each host patch they encounter in an optimal way in order to maximize their rate of progeny production (see van Alphen \& Vet 1986; for a review).

When the distribution of hosts is known by a parasitoid female, the optimal foraging time she should invest on each patch can be predicted from the wellknown Marginal Value Theorem (Charnov 1976). This

Correspondence: Eric Wajnberg, INRA, 37 Boul. du Cap, 06600 Antibes, France. Tel. (33) 493678892; Fax: (33) 493678897; E-mail: wajnberg@antibes.inra.fr model predicts that, in order to maximize its rate of progeny production, the female should leave each patch she exploits when the instantaneous rate of fitness return from the patch falls below the mean rate of return for the whole environment. Despite the fact that good qualitative experimental verifications of this theoretical prediction have been found (see Nonacs 2001 for a recent review), parasitoid females cannot be expected to have accurate knowledge of the exact distribution of hosts in their habitat. It is more realistic to consider that females are collecting some information while foraging and are using proximate behavioural patch-leaving decision rules to adjust their foraging time in an optimal way (Green 1984; van Alphen \& Vet 1986; Godfray 1994; Wajnberg, Fauvergue \& Pons 2000).

Among the different patch-leaving rules that have been proposed, the one suggested by Waage (1979) is probably the most well-known. By studying patch time allocation in the larval parasitoid Venturia canescens (Gravenhorst), he showed that a female entering a patch will start to search for hosts with some level of 
619

Comparative analysis of patch-leaving rules

(C) 2003 British

Ecological Society, Journal of Animal Ecology, 72, 618-626 'responsiveness', which is related to the number of hosts available. This responsiveness corresponds to a tendency to turn sharply when the edge of the patch is reached, and so reflects a tendency to remain in the patch. The responsiveness then decreases progressively until a threshold is reached, causing the wasp to leave. Each successful host attack has an incremental influence on the responsiveness, thereby increasing the total residence time (Waage 1978, 1979). More recently it has been shown that, for some species, attacking a host could also lead to a decremental effect on responsiveness. Such a decremental effect is usually called a 'count-down' mechanism (Driessen et al. 1995; Driessen \& Bernstein 1999; Wajnberg, Rosi \& Colazza 1999). Incremental mechanisms have been showed to be adaptive when the female has little or no prior information of host availability in the patch, and this should be the case when there is a large heterogeneity in patch quality in the environment. On the other hand, a countdown mechanism has been shown to perform better when the female is well informed about patch quality, which is likely to be the case when all patches contain a relatively uniform number of hosts (Iwasa, Higashi \& Yamamura 1981; Driessen \& Bernstein 1999).

It has been pointed out repeatedly that the behavioural mechanisms by which a female adjusts its patch residence time should vary among species, especially if they are known to attack different host species showing different spatial distribution patterns. However, a description of interspecific variation, based on an accurate phylogenetic approach, has never been conducted. Only a few studies have been undertaken to compare the foraging behaviour of related parasitoid species (Vet \& Bakker 1985; Vet \& van Alphen 1985; Poolman Simons et al. 1992; Geervliet et al. 1993; Vet et al. 1993). However, as far as patch time allocation is concerned, only Vos, Hemerik \& Vet (1998) compared two Cotesia species (Hymenoptera: Braconidae), one specialist and one generalist, and a difference in the patchleaving decision rules adopted by these two species was discovered. The phylogenetic history of a species is necessarily implicated in its evolutionary response to environmental variation. Therefore, an accurate comparison of phylogenetically related species should lead to a better understanding of the interaction between phylogenetic and ecological constraints (Wanntorp 1983; van Alphen \& Vet 1986; Godfray 1994).

There is thus a need for the development of phylogenetically based comparative analyses among species, and this was the aim of the present study. Patch-leaving decision rules were studied in 17 egg parasitoid species (and populations), all belonging to the Trichogrammatidae (Hymenoptera) family. The behavioural mechanisms adopted by the females were identified and compared by means of a Cox's (1972) proportional hazards model, a statistical method that appears to be particularly appropriate for analysing data on time allocation (see van Alphen 1993; Vos et al. 1998; Wajnberg et al. 1999, 2000). The Trichogrammatidae family was chosen because the phylogenetic relationships among species are now known accurately (Pintureau 1987; Pinto \& Stouthamer 1994). Moreover, the behaviour of females foraging for hosts has already been described accurately (Morrison \& Lewis 1981; Gardner \& van Lenteren 1986; Schmidt 1994; Wajnberg et al. 2000).

Results indicated that there was strong interspecific variation in the patch-leaving mechanisms used by the different species. A comparative analysis using the method of phylogenetically independent contrasts (Felsenstein 1985) enabled us to show that such interspecific variation could not be explained by the phylogenetic relationships among the species compared. The adaptive and evolutionary meaning of these results is discussed.

\section{Materials and methods}

\section{INSECTS AND EXPERIMENTAL SET-UP}

The Trichogrammatidae (Hymenoptera: Chalcidoidea) is a family of tiny wasps ( $1 \mathrm{~mm}$ or less), all of which are oophagous parasitoids that are usually not strictly host-specific. The family consists of more than 80 genera, but the two closely related genera Trichogramma and Trichogrammatoidea have received most attention because of their importance in biological control programmes (Wajnberg \& Hassan 1994). The behaviour of a female attacking a host is fixed across all species. Before attempting to oviposit into a potential host, the female examines the host surface by walking on it while drumming it continuously with its antennae. If the host is accepted, the female starts to drill through the host chorion with its ovipositor, and then adopts an oviposition posture while laying one or more egg(s) into the host. Finally, the attacked host is marked. The marking compounds are used by the females to discriminate between healthy and previously parasitized hosts (Salt 1937; Klomp, Teerink \& Ma 1980).

Table 1 provides a list of the 17 species and populations compared with their geographical origin. All the strains entered our rearing system between 1996 and 2000, and their specific status was checked regularly by B. Pintureau (Villeurbanne, France). From the time of capture onwards, the strains were maintained under laboratory conditions on Ephestia kuehniella Zeller (Lepidoptera: Pyralidae) eggs at $25^{\circ} \mathrm{C}$, LD $12: 12$.

For each strain, females $<24 \mathrm{~h}$ old were offered individually a single patch of three UV-killed E. kuehniella eggs arranged in a triangle of $1 \mathrm{~mm}$ on a side. UV-killed eggs prevent hatching of the host larvae and are known to remain suitable for parasitism (Goldstein 1983). Females were all virgin, honey-fed and were not allowed to contact any host before the experiment (i.e. naive females). They were used only once and were free to leave the patch whenever they wanted. Attacked hosts were not replaced. A total of 309 females was measured, representing an average of 18.2 individuals 
Table 1. List of the species compared with their geographical origin. Upper-case letters indicate different populations of the same E. Wajnberg et al. species

\begin{tabular}{llll}
\hline No. & Name & Origin & Authors \\
\hline 1 & Trichogrammatoidea bactrae & Thailand & Nagaraja \\
2 & Trichogramma bourarachae & Morocco & Pintureau \& Babault \\
3 & Trichogramma buesi $\mathrm{A}$ & France & Voegelé \\
4 & Trichogramma buesi B & Canada & Voegelé \\
5 & Trichogramma cacoeciae & Canada & Marshal \\
6 & Trichogramma chilonis A & China & Ishii \\
7 & Trichogramma chilonis B & Japan & Ishii \\
8 & Trichogramma chilonis C & La Réunion Island & Ishii \\
9 & Trichogramma chilonis D & Taiwan & Ishii \\
10 & Trichogramma dendrolimi & Italy & Matsumura \\
11 & Trichogramma exiguum & USA & Pinto \& Platner \\
12 & Trichogramma evanescens A & France & Westwood \\
13 & Trichogramma evanescens B & Canada & Westwood \\
14 & Trichogramma oleae & France & Voegelé \& Pointel \\
15 & Trichogramma principium & Syria & Sugonaev \& Sorokina \\
16 & Trichogramma semblidis & France & Aurivillius \\
17 & Trichogramma vogelei & France & Pintureau \\
\hline
\end{tabular}

(range: 10-20) per strain, and females of all strains were distributed randomly over all the days of the experiment. All replicates were carried out during daytime, at $25 \pm 1{ }^{\circ} \mathrm{C}$ and $60 \pm 5 \% \mathrm{RH}$.

The behaviour of each female was observed continuously from the moment the parasitoid entered the patch for the first time up to the moment it left the patch for more than $60 \mathrm{~s}$. On some occasions, the females left the patch and walked a few millimetres away before returning to the hosts. As in Driessen \& Bernstein (1999) and in Wajnberg et al. (2000), these short excursions were included in the computation of the patch residence time.

Using an event recorder, the beginning and the end of the following behaviours were recorded during the whole observation with an accuracy of $0 \cdot 1 \mathrm{~s}$ : (1) entering or (2) leaving the patch, (3) antennal drumming on a host, (4) drilling a host with the ovipositor, (5) ovipositing in a host and (6) walking between hosts. The location of the host on which behaviours 3-5 were observed was also recorded. A drilling behaviour followed by an oviposition behaviour was considered to be a successful host attack behaviour. When there was no oviposition after a drilling behaviour, the host was considered to be rejected.

\section{STATISTICAL ANALYSIS}

The patch-leaving decision rules used by the females were identified from the experimental data and compared among the species/populations by means of a proportional hazards model (Cox 1972). A thorough description of this model can be found in the literature dealing with survival analysis (e.g. Kalbfleisch \& Prentice 1980; Collett 1994). This particular model has already been used successfully by several authors to identify patch-leaving mechanisms used by several parasitoid species (e.g. Haccou et al. 1991; Hemerik,
Driessen \& Haccou 1993; van Roermund, Hemerik \& van Lenteren 1994; Driessen \& Bernstein 1999; Wajnberg et al. 1999, 2000). Briefly, the model focuses on the patch-leaving tendency (the so-called hazard rate), which is the probability per unit of time that a female leaves the patch, given that she is still on it. This leaving tendency, which is a function of time, is assumed to be a product between a baseline leaving tendency and a positive exponential term (the so-called hazard ratio) representing the joint effect of predefined explanatory factors (i.e. covariates). The general form of the model is:

$h(t)=h_{0}(t) \exp \left\{\sum_{i=1}^{p} \beta_{i} z_{i}\right\}$

in which $h(t)$ is the hazard rate, $h_{0}(t)$ is the baseline patch-leaving tendency (so-called baseline hazard), $t$ the time passed since the female entered the patch and $\beta_{i}$ the regression coefficients that give the relative contributions of $p$ covariates $z_{i}$. The effect of the covariates is given by the value of the hazard ratio. If this exponential term is lower than 1 the patch-leaving tendency of the females is reduced; above 1, the patch-leaving tendency is increased. Finally, the values of the explanatory covariates can change over the course of time or can be fixed, and the baseline hazard is the patchleaving tendency when all covariates are equal to zero.

As was performed in several other studies (e.g. Haccou et al. 1991; Hemerik et al. 1993; van Roermund et al. 1994; Wajnberg et al. 1999, 2000), the number of successful ovipositions and the number of host rejections were used as covariates in order to understand their influence on the females' patch-leaving tendency. This enables us to quantify the associated incremental or decremental effect on patch residence time. However, in the present study the location of all hosts attacked was recorded continuously for all replicates. 
621

Comparative analysis of patch-leaving rules
(C) 2003 British

Ecological Society, Journal of Animal Ecology, 72, 618-626
This enabled us to discriminate between a successful attack and a host rejection of a healthy host or of a host attacked previously by the female, thus leading to four different time-dependent covariates. Because only one population was studied for most of the species compared (see Table 1), we were not able to test separately the variation between species and variation among populations (within species). We thus decided to test globally the interstrain (i.e. species/populations) variability by adding a fixed categorical covariate. The first strain (i.e. Trichogrammatoidea bactrae Nagaraja) was assumed arbitrarily to be the reference level corresponding to the baseline hazard with a parameter set to zero (see Collett 1994; Wajnberg et al. 1999; for a detailed explanation). Finally, the interactions between the fixed covariate and the four time-dependent covariates were also added to the model in order to quantify changes in the patch-leaving mechanisms among the strains compared. All the regression coefficients and their variance-covariance matrix were estimated from the data by partial likelihood maximization (Cox 1975). In turn, these were used to compute confidence intervals of species-specific hazard ratios (see Wajnberg et al. 1999; for a detailed explanation).

Several statistical procedures are available for testing the significant effect of the covariates, all of which take into account the existence of possible correlations among the corresponding parameters. In the present study, as in Wajnberg et al. (1999), the significant effect of the covariates was tested using standard likelihood ratio tests through an iterative procedure to identify the parameters having a significant influence on the females' patch-leaving tendency. The adequacy of the final fitted model was assessed by making residual plots (see Wajnberg et al. 1999; for an example of such a plot). Results showed that the fitting procedure led to a final model that properly described the patch-leaving mechanisms used by all strains of the parasitoid females. All computations were conducted in S-Plus (Venables \& Ripley 1994).

\section{Results}

There was strong variation in the average patch residence time among the parasitoid strains compared (range: 467-841 s; log-rank test: $\chi^{2}=43 \cdot 31$, d.f. $=16, P<0 \cdot 001$ ) (see Fig. 1). Under identical experimental conditions, females of some strains foraged on the available host patch almost twice as long as some other strains.

The patch-leaving mechanisms used by the females of the different strains were identified by means of a proportional hazards model. Table 2 gives the estimated effects of all the covariates having a significant influence on the females' patch-leaving tendency. The tendency of the females to leave the patch clearly varied among the different strains compared. Furthermore, on average, each successful oviposition in a healthy host significantly increased the patch-leaving tendency by a factor of 1.46. This indicates that, on average, Trichogrammatidae females are using a decremental mechanism to manage their patch residence time. The same average mechanism was observed each time females rejected a host that they previously attacked. In this case, the patch-leaving tendency was increased by a factor of $1 \cdot 38$. In contrast, despite these events being not particularly rare (rates: $12 \cdot 80 \pm 2 \cdot 24 \%$ and $10 \cdot 47 \pm$ $3 \cdot 47 \%$, respectively), rejecting a healthy host or attacking a host a second time (or more) did not show any effect on the females' patch-leaving tendency (all $\chi^{2}$ at $P>0 \cdot 05)$.

Besides these main effects, there was also a significant interaction between the strains compared and the influence of the number of ovipositions in a healthy host or the number of rejections of a host already attacked. These two significant interactions, which are represented graphically in Fig. 2, indicate that the

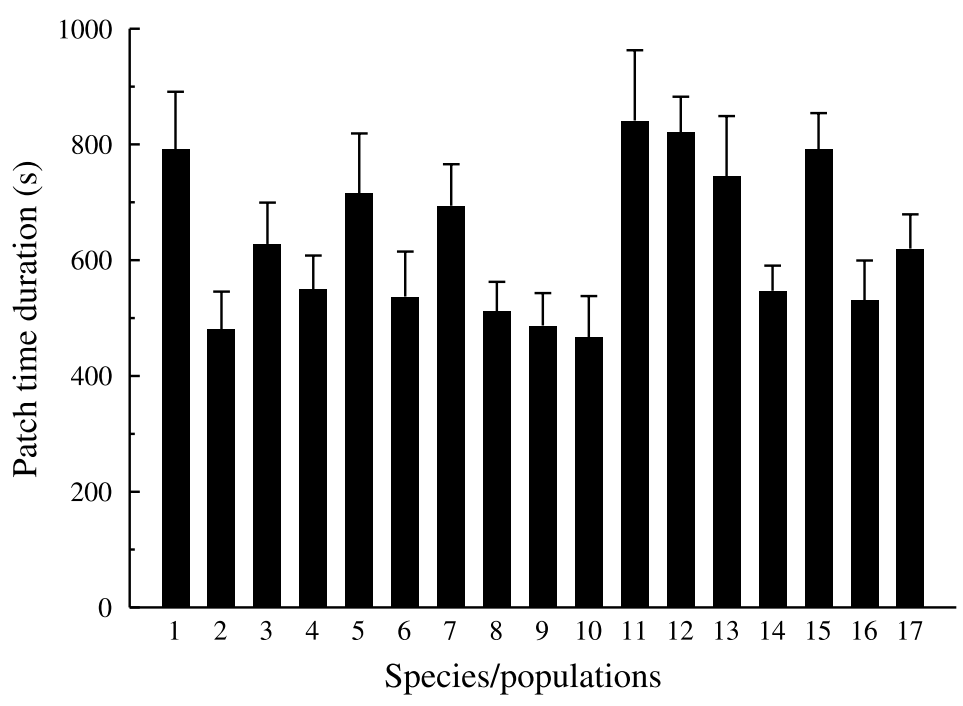

Fig. 1. Average (+ SE) patch residence time for the 17 species/populations compared. The code number of the species is indicated in Table 1. Both averages and standard errors are computed from the Kaplan-Meier estimator of the corresponding survivor functions. 
622

E. Wajnberg et al.

Table 2. Estimated regression coefficients $(\beta)$, standard errors $(\mathrm{SE})$ and hazard ratio $(\exp (\beta))$ for only the covariates having a significant effect $(P<0 \cdot 05)$ on the patch-leaving tendency of Trichogrammatidae females. $\chi^{2}$ correspond to standard likelihood ratio tests. For each covariate including the 'species/population' effect, 16 parameters are estimated. They are not provided here

\begin{tabular}{lllllr}
\hline & $\beta$ & SE & $\exp (\beta)$ & $\chi^{2}($ d.f.) & $P$-value \\
\hline Species/population the female belongs to (1) & - & - & - & $55 \cdot 19(16)$ & $<0.001$ \\
Oviposition in a healthy host (2) & 0.380 & 0.106 & 1.46 & $12 \cdot 92(1)$ & $<0.001$ \\
Rejection of a host previously attacked (3) & 0.322 & 0.070 & 1.38 & $23.56(1)$ & $<0.001$ \\
Interaction (1)-(2) & - & - & - & $26 \cdot 86(16)$ & 0.040 \\
Interaction (1)-(3) & - & - & - & $43.93(16)$ & $<0.001$ \\
\hline
\end{tabular}

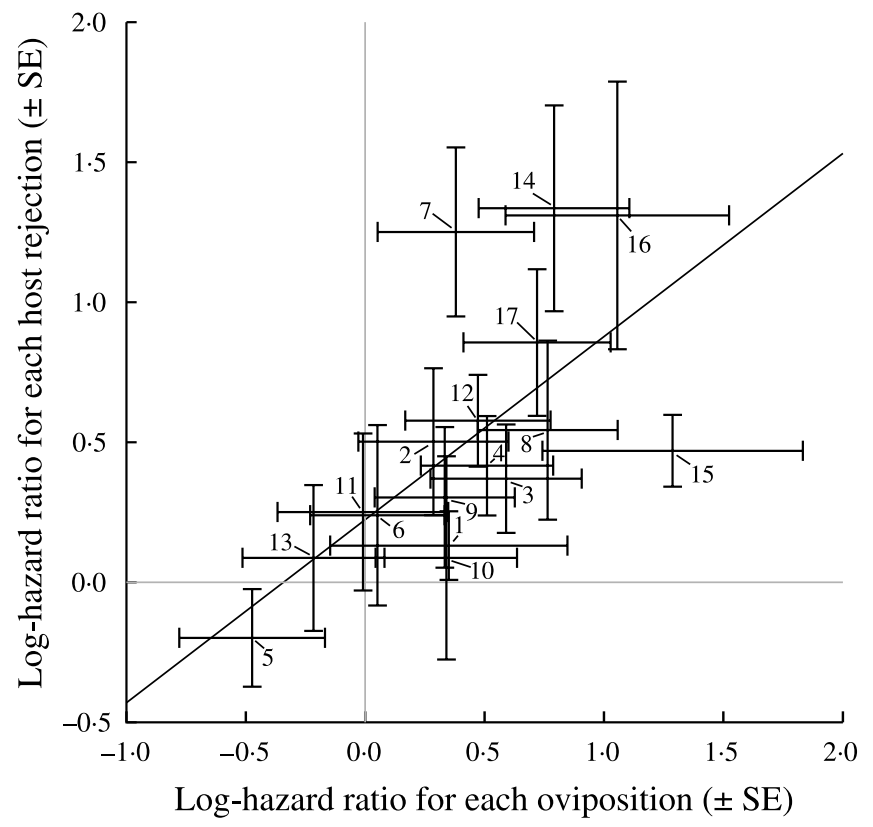

Fig. 2. Graphical representation of interstrain variation in the effect of each successful oviposition in a healthy host ( $x$-axis) or each rejection of an already attacked host ( $y$-axis). Log-hazard ratios and their SE are computed from the fitted proportional hazards model (see text). The code number of the species/populations is the one indicated in Table 1. For both axes, negative values correspond to an incremental influence on the females' patch-leaving tendency. Positive values correspond to a decremental effect. The diagonal line corresponds to the linear regression between the average points. The linear correlation between the average points is $0 \cdot 643(n=17, P=0 \cdot 005)$.

influence of the two time-dependent covariates differed among the 17 strains compared. For both patchleaving mechanisms, this interstrain variation within the Trichogrammatidae family appeared to be strong, ranging from incremental to decremental effects (see Fig. 2). Finally, the interstrain variation in the two patch-leaving mechanisms appeared to be correlated positively. Females belonging to species that showed a strong decremental effect associated with each successful oviposition were also those that showed a strong decremental effect associated with each rejection of a previously parasitized host (e.g. Trichogramma semblidis Aurivillius, species no. 16). For others, such as Trichogramma cacoeciae Marshal females (species no. 5), both mechanisms appeared to have an incremental influence on their patch residence time.

From a statistical point of view, the test of the correlation shown in Fig. 2 assumes that all strains are independent points (Sokal \& Rohlf 1995). However, as pointed out by Felsenstein (1985), such an assumption is not valid here because, as can be seen in Fig. 3, the different strains are related phylogenetically. The significant correlation found between the two patchleaving mechanisms could thus be spurious, being an artefact of the non-independence of the species. In such a case, the correlation might come from the fact that all strains share a common ancestor. The correlation would thus not have an adaptive meaning at the present time (Harvey \& Pagel 1991; Martins 1996). Several methods have been proposed to overcome this problem (Rohlf 2001). One of the most commonly used ones is the method of phylogenetically independent contrasts of Felsenstein (1985), which is based on the fact that, even if species are non-independent, the differences between them are (Garland, Midford \& Ives 1999). This method was applied to the data shown in Fig. 2, and the computations were performed using COMPARE version $4 \cdot 4$, a computer package developed by E.P. Martins (Martins 2001). The interstrain correlation between the two patch-leaving mechanisms, free of 
623

Comparative analysis of patch-leaving rules
(C) 2003 British

Ecological Society, Journal of Animal Ecology, 72, 618-626

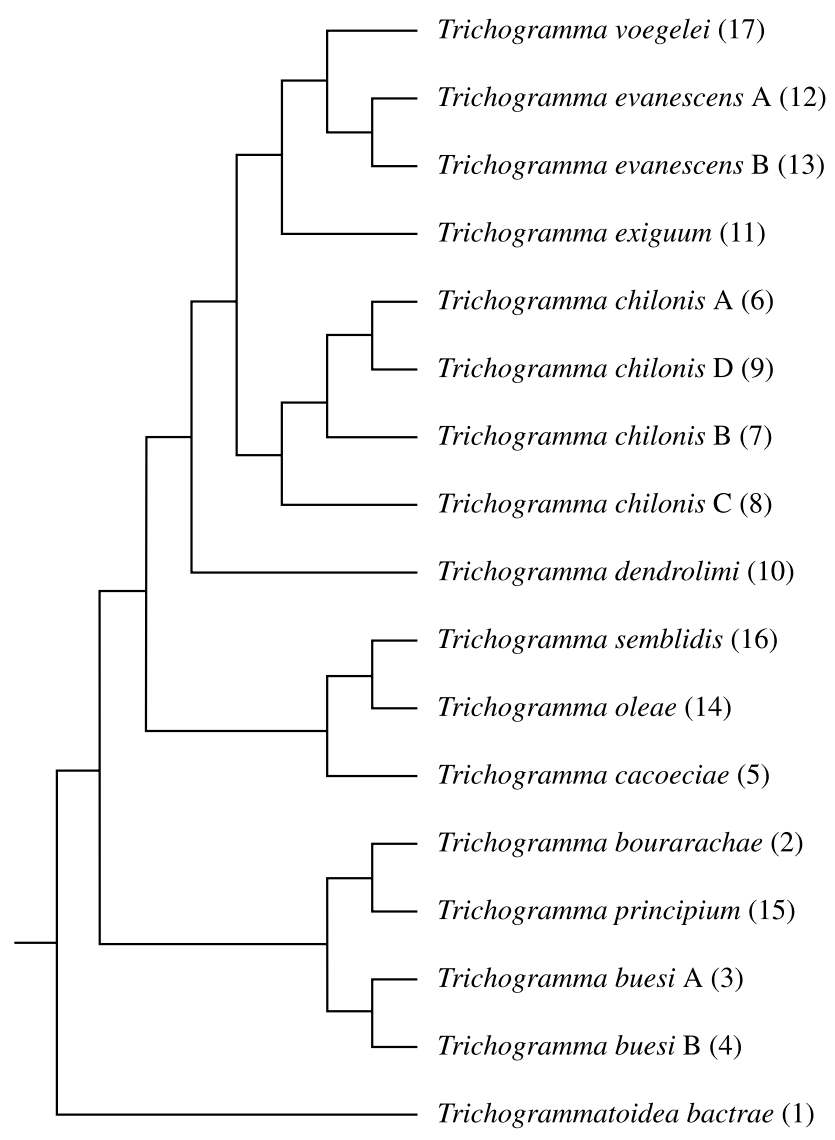

Fig. 3. Reconstructed tree showing the phylogenetic relationships among the Trichogrammatidae species compared (from Pintureau 1987). The geographical origin of the populations was used to estimate their level of relatedness. Branch lengths are set using the arbitrary Pagel's (1992) method (i.e. all internode branch segments are set equal to one, but tips are constrained to be contemporaneous). Numbers in brackets correspond to those indicated in Table 1.

phylogenetic effect, remained highly significant $(r=$ $0 \cdot 667$, d.f. $=15, P<0 \cdot 005)$. The computation was performed using the arbitrary branch lengths of Pagel (1992) (see Fig. 3). Other branch lengths were also tested (e.g. all branch lengths equal to one, etc.: see DiazUriarte \& Garland 1998 for a detailed discussion). All results led always to highly significant positive correlations. The method of phylogenetically independent contrasts used here assumes that the data analysed have resulted from an evolutionary process similar to Brownian motion, which implies that the characters have evolved randomly via a neutral, gradual process at each time unit. This is not necessarily the case, and there has been some discussion recently about whether alternative methods should be used, especially for traits undergoing adaptive evolution (e.g. Westoby, Leishman \& Lord 1995; Diaz-Uriarte \& Garland 1996; Martins 2000). As suggested by Martins, Diniz-Filho \& Housworth (2002), a possible strategy could be to apply a combination of different methods based on different assumptions. Thus, two additional phylogenetic comparative methods were applied on the data shown in Fig. 2: the spatial autoregressive method of Cheverud, Dow \& Leutenegger (1985) and the phylogenetic generalized least-squares regression of Martins \& Hansen (1997). In both cases, the correlation obtained between the two patch-leaving rules remained both positive and highly significant. Thus, the global conclusion remains the same: the positive interstrain correlation observed between the two patch-leaving mechanisms adopted by the Trichogrammatidae females cannot be explained by the fact that the strains are related phylogenetically.

\section{Discussion}

Under standardized laboratory conditions the results obtained here demonstrated, within the Trichogrammatidae family, the existence of strong interspecific variation in the time allocated by females to host patches. Theory predicts that wasps with a short life expectancy should invest more foraging time on each host patch encountered because they have less opportunity to find other unexploited patches during their lifetime (Roitberg et al. 1992). Thus, it might be possible that the interspecific variation observed in females' patch residence time could be the result of a correlated variation in their life expectancy. In order to test such an hypothesis, average adult lifetime duration of the females was quantified under standardized laboratory conditions for the 17 strains compared. The correlation with the average patch residence time was not 
624

E. Wajnberg et al.

significant $(r=0 \cdot 07, P>0 \cdot 70)$. Thus, variation in adults'

life expectancy cannot explain the interstrain variation observed in patch time allocation, and other explanations should be proposed.

According to Waage's (1979) model, the patch residence time should depend (1) on the initial degree of responsiveness to the patch quality, which is related to the number of hosts available, and (2) on the decreasing rate of this responsiveness during foraging time, which corresponds to a decreasing tendency to turn sharply each time the patch edge is reached (Waage 1978, 1979). The interstrain variation observed in this study cannot be explained by a variation in the initial estimate of patch quality, because patches offered to the females were all comprised identically of three hosts. Therefore, the probable explanation of the interstrain variation observed is that differences exist in the rate of habituation to the patch edge and/or in the threshold level in the responsiveness below which the patch is left. Such a variability would correspond to a variation in the so-called 'arrestment response' of the parasitoid, which is characterized by a reduction in walking speed and an increase in the rate of turning when hostassociated cues are found (Waage 1978; Gardner \& van Lenteren 1986; van Alphen \& Vet 1986).

Our results also showed that, on average, each successful oviposition significantly increased the females' patch-leaving tendency. This indicates that, on average, Trichogrammatidae females were using a decremental mechanism similar to the 'count-down' mechanism proposed by Driessen et al. (1995). Actually, the results show that, within the Trichogrammatidae family, there is interspecific variation in this patch-leaving mechanism. Some species appeared to use an incremental mechanism, as was shown previously in Trichogramma brassicae (Wajnberg et al. 2000), while the majority of species appeared to be on the decremental side (see Fig. 2). A possible explanation of such interspecific variation is suggested by the work of Rosenheim \& Mangel (1994). Using a theoretical approach, these authors demonstrated that females showing an imperfect ability to discriminate between healthy and already parasitized hosts within the patch should leave earlier in order to reduce the risk of superparasitism, with a corresponding reduction in reproductive success. An increase in the patch-leaving tendency after each oviposition could be the corresponding behavioural mechanism (Tenhumberg et al. 2001). Under this hypothesis, the interspecific variation observed in such a patch-leaving rule could be the result of a corresponding variation in the level of species-specific discrimination ability.

Iwasa et al. (1981) demonstrated that a decrease in the willingness to remain on the patch after each oviposition should maximize the parasitoid's rate of fitness return if all patches contain a uniform number of hosts. This is because the parasitoid should know how many hosts are present in the patch (Shaltiel \& Ayal 1998; Vos et al. 1998). On the other hand, when there is a large variance in the quality of available patches, wasps should have little or no prior information of host availability and an incremental mechanism is shown to perform better. Therefore, the interspecific variation observed in the change in patch-leaving tendency after each oviposition is likely related to variation in the distribution pattern of hosts attacked by the different strains and/or in the ability of females to have prior information of host availability upon entering the patch. Trichogrammatidae species are known to be polyphagous. The hosts attacked range from species that lay isolated eggs (i.e. with a minimal variance in patch quality) to species that lay large egg masses with large variability in size. Unfortunately, no accurate information is available on the ecology and distribution pattern of all potential host species, and this plausible hypothesis cannot be verified.

In all theoretical and experimental works conducted on patch-leaving decision rules, results concerning the influence of each oviposition are always presented in a dichotomous way: the effect can be only incremental or decremental (e.g. Vos et al. 1998; Driessen \& Bernstein 1999; Wajnberg et al. 2000). However, the interspecific variation shown in Fig. 2 suggests that the effect of each oviposition should, rather, be considered to present a continuous variation between these two opposite effects. Even at the intrapopulation level, Wajnberg et al. (1999), working on the parasitoid Telenomus busseolae (Hymenoptera: Scelionidae), demonstrated the existence of significant genetic variability in this behavioural mechanism, thus reinforcing the continuous status of the variation in this patch-leaving rule.

Rejecting a previously attacked host led also, on average, to a significant increase in the females' patchleaving tendency. Such a behavioural mechanism has already been shown in several other parasitoid species, and has always been considered to be adaptive. This is because the rejection of a host provides the female with some information regarding the decreasing value of the patch, and it becomes less and less worthwhile for the female to remain on it (van Alphen \& Vet 1986; van Lenteren 1991; van Alphen 1993). For this patchleaving mechanism, substantial variation was also observed among the different strains (see Fig. 2). In this case, all the species but one (i.e. T. cacoeciae, species no. 5) showed a decremental effect. The decremental influence of rejecting a previously parasitized host is thought usually to be the result of two different mechanisms. The ability to discriminate between healthy and previously parasitized hosts may allow the female to perceive the decreasing rate of finding unparasitized hosts and thus impart information to the parasitoid about the increasing level of patch exploitation. Also, rejecting an already parasitized host may simply decrease the wasp's host-searching motivation (van Alphen \& Vet 1986; van Alphen 1993). Thus, the interspecific variation observed in the effect of each parasitized host rejected could be the result of an interstrain variation in discrimination ability and/or in 
Comparative analysis of patch-leaving rules

some associated decrease in females' host-searching motivation.

From a neuroethological viewpoint, the incremental and decremental effects associated to each oviposition or host rejection are usually considered to be related to neurophysiological mechanisms such as excitation and habituation, respectively (Stephens \& Krebs 1986; Driessen \& Bernstein 1999). Thus, the interspecific variability observed in these two patch-leaving behavioural rules could be the result of variation in the intensity of such neural mechanisms, and thus on the dynamics of the peripheral sensory receptors involved. Unfortunately, it would be almost impossible to measure accurately the interspecific variation in such neurophysiological processes on Trichogrammatidae females because of their minute size.

Finally, there was a significant positive relationship between the interspecific variation in the two patchleaving rules adopted by the Trichogrammatidae females. This positive relationship remained significant when the phylogenetic relationship between the strains was controlled with the use of phylogenetic comparative methods. Therefore, such a positive relationship cannot be inferred to come from a common ancestral species. Two explanatory hypotheses can be proposed. Such a correlation could have been maintained in the course of evolutionary time because it may have some adaptive meaning on parasitoids' fitness in all species. Such adaptive meaning could probably be related to the ecology and distribution patterns of all the potential hosts that can be attacked. Another hypothesis is that the neurosensory receptors involved in these two patch-leaving mechanisms would simply be the same in each of the strains compared. In turn, any source of interspecific variation in their effect will lead to the positive correlation observed.

Whatever the real significance of such results, it is clear that the comparative analysis of the proximate mechanisms involved in patch time allocation in insect parasitoid species has led to a better understanding of their ecology and behaviour. In turn, especially when the species could be used for biological control programmes against phytophagous pests, as is generally the case for the Trichogrammatidae family, such a study should help in optimizing the choice of the proper species to control a given pest, on a given crop and in a given environment.

\section{Acknowledgements}

We thank B. Pintureau for identifying all the species used in this research. The Biotop society (France), G. Boivin (Canada), R. Goebel (La Réunion Island), M. Legrand (France), K. Miura (Japan), B. Pintureau (France), the Tomen Society (Japan) and C. Trouvé

(C) 2003 British

Ecological Society, Journal of Animal Ecology, 72, 618-626 (France) are thanked for providing us with some of the species/populations compared. F. Dubois and S. Morand are thanked for their help in developing a comparative analysis of the data obtained. C. Bernstein,
F. Dubois, R.H. Messing, S. Morand, O. Pons and J.S. Pierre are thanked for their encouragement and their critical reading of the manuscript. This work has been done within the framework of the GDR CNRS \# 2155 'Écologie Comportementale'.

\section{References}

van Alphen, J.J.M. (1993) Patch residence time and encounters with parasitized hosts: a reaction. Netherlands Journal of Zoology, 43, 340-349.

van Alphen, J.J.M. \& Vet, L.E.M. (1986) An evolutionary approach to host finding and selection. Insect Parasitoids (eds J. Waage \& D. Greathead), pp. 23-61. Academic Press, London.

Charnov, E.L. (1976) Optimal foraging: the marginal value theorem. Theoretical Population Biology, 9, 129-136.

Cheverud, J.M., Dow, M.M. \& Leutenegger, W. (1985) The quantitative assessment of phylogenetic constraints in comparative analyses: sexual dimorphism in body weight among primates. Evolution, 39, 1335-1351.

Collett, D. (1994) Modelling Survival Data in Medical Research Chapman \& Hall, London.

Cox, D.R. (1972) Regression models and life tables. Biometrics, 38, 67-77.

Cox, D.R. (1975) Partial likelihood. Biometrika, 62, 269-276.

Diaz-Uriarte, R. \& Garland, T. Jr (1996) Testing hypotheses of correlated evolution using phylogenetically independent contrasts: sensitivity to deviations from Brownian motion. Systematic Biology, 45, 27-47.

Diaz-Uriarte, R. \& Garland, T. Jr (1998) Effects of branch length errors on the performance of phylogenetically independent contrasts. Systematic Biology, 47, 654-672.

Driessen, G. \& Bernstein, C. (1999) Patch departure mechanisms and optimal host exploitation in an insect parasitoid. Journal of Animal Ecology, 68, 445-459.

Driessen, G., Bernstein, C., van Alphen, J.J.M. \& Kacelnik, A. (1995) A count-down mechanism for host search in the parasitoid Venturia canescens. Journal of Animal Ecology, 64, 117-125.

Emlen, J.M. (1966) The role of time and energy in food preference. American Naturalist, 100, 611-617.

Felsenstein, F. (1985) Phylogenies and the comparative method. American Naturalist, 125, 1-15.

Gardner, S.M. \& van Lenteren, J.C. (1986) Characterisation of the arrestment responses of Trichogramma evanescens. Oecologia, 68, 265-270.

Garland, T. Jr, Midford, P.E. \& Ives, A.R. (1999) An introduction to phylogenetically based statistical methods, with a new method for confidence intervals on ancestral states. American Zoologist, 39, 374-388.

Geervliet, J.B.F., van Aaken, R., Savelkoul, C., ter Smette, S.M., Brodeur, J., Vet, L.E.M. \& Dicke, M. (1993) Comparative approach to infochemical use by parasitoids for the case of Cotesia glomerata and Cotesia rubecula. Proceedings of the Society for Experimental and Applied Entomology, 4, 33-38.

Godfray, H.C.J. (1994) Parasitoids. Behavioral and Evolutionary Ecology. Princeton University Press, New Jersey.

Goldstein, L.F. (1983) Rearing Trichogramma nubilale (Hymenoptera: Trichogrammatidae) on ultra-violet-irradiated eggs of the European corn borer (Lepidoptera: Pyralidae). Journal of Economic Entomology, 76, 969-971.

Green, R.F. (1984) Stopping rules for optimal foragers. American Naturalist, 123, 30-40.

Haccou, P., de Vlas, S.J., van Alphen, J.J.M. \& Visser, M.E. (1991) Information processing by foragers: effects on intrapatch experience on the leaving tendency of Leptopilina heterotoma. Journal of Animal Ecology, 60, 93-106.

Harvey, P.H. \& Pagel, M.D. (1991) The Comparative Method in Evolutionary Biology. Oxford Series in Ecology and Evolution. Oxford University Press, Oxford. 
E. Wajnberg et al.
Hemerik, L., Driessen, G. \& Haccou, P. (1993) Effects of intra-patch experiences on patch time, search time and searching efficiency of the parasitoid Leptopilina clavipes. Journal of Animal Ecology, 62, 33-44.

Iwasa, Y., Higashi, M. \& Yamamura, N. (1981) Prey distribution as a factor determining the choice of optimal foraging strategy. American Naturalist, 117, 710-723.

Kalbfleisch, J.D. \& Prentice, R.L. (1980) The Statistical Analysis of Failure Time Data. Wiley, New York.

Klomp, H., Teerink, B.J. \& Ma, W.C. (1980) Discrimination between parasitized and unparasitized hosts in the egg parasite Trichogramma embryophagum (Hym., Trichogrammatidae): a matter of learning and forgetting. Netherlands Journal of Zoology, 30, 254-277.

van Lenteren, J.C. (1991) Encounters with parasitized hosts: to leave or not to leave a patch. Netherlands Journal of Zoo$\log y, 41,144-157$.

MacArthur, R.H. \& Pianka, E.R. (1966) On optimal use of a patchy environment. American Naturalist, 100, 603-609.

Martins, E.P. (1996) Phylogenies and the Comparative Method in Animal Behaviour Oxford University Press, Oxford.

Martins, E.P. (2000) Adaptation and the comparative method. Trends in Ecology and Evolution, 15, 295-299.

Martins, E.P. (2001) COMPARE, version 4.4. Computer programs for the statistical analysis of comparative data. Distributed by the author via http://compare.bio.indiana.edu/.

Martins, E.P., Diniz-Filho, J.A. \& Housworth, E.A. (2002) Adaptive constraints and the phylogenetic comparative method: a computer simulation study. Evolution, 56, 1-13.

Martins, E.P. \& Hansen, T.F. (1997) Phylogenies and the comparative method: a general approach to incorporating phylogenetic information into analysis of interspecific data. American Naturalist, 149, 646-667.

Morrison, G. \& Lewis, W.J. (1981) The allocation of searching time by Trichogramma pretiosum in host-containing patches. Entomologia Experimentalis et Applicata, 30, 31-39.

Nonacs, P. (2001) State dependent behavior and the Marginal Value Theorem. Behavioral Ecology, 12, 71-83.

Pagel, M.D. (1992) A method for the analysis of comparative data. Journal of Theoretical Biology, 156, 431-442.

Pinto, J.D. \& Stouthamer, R. (1994) Systematics of the Trichogrammatidae with emphasis on Trichogramma. Biological Control with Egg Parasitoids (eds E. Wajnberg \& S.A. Hassan), pp. 1-36. CAB International, Wallingford, UK.

Pintureau, B. (1987) Systématique évolutive du genre Trichogramma Westwood en Europe. Thesis, Université Paris VII

Poolman Simons, M.T.T., Suverkropp, B.P., Vet, L.E.M. \& de Meod, G. (1992) Comparison of learning in related generalist and specialist eucoilid parasitoids. Entomologia Experimentalis et Applicata, 64, 117-124.

van Roermund, H.J.W., Hemerik, L. \& van Lenteren, J.C. (1994) Influence of intrapatch experiences and temperature on the time allocation of the whitefly parasitoid Encarsia formosa (Hymenoptera: Aphelinidae). Journal of Insect Behavior, 7, 483-501.

Rohlf, F.J. (2001) Comparative methods for the analysis of continuous variables: geometric interpretations. Evolution, $\mathbf{5 5}, 2143-2160$

Roitberg, B.D., Mangel, M., Lalonde, R.G., Roitberg, C.A., van Alphen, J.J.M. \& Vet, L. (1992) Seasonal dynamics shifts in patch exploitation by parasitic wasps. Behavioral Ecology, 3, 156-165.
Rosenheim, J.A. \& Mangel, M. (1994) Patch-leaving rules for parasitoids with imperfect host discrimination. Ecological Entomology, 19, 374-380.

Salt, G. (1937) The sense used by Trichogramma to distinguish between parasitised and unparasitised hosts. Proceedings of the Royal Society of London Series B, 122, 57-75.

Schmidt, J.M. (1994) Host recognition and acceptance by Trichogramma. Biological Control with Egg Parasitoids (eds E. Wajnberg \& S.A. Hassan), pp. 166-200. CAB International, Wallingford, UK.

Shaltiel, L. \& Ayal, Y. (1998) The use of kairomones for foraging decisions by an aphid parasitoid in small host aggregations. Ecological Entomology, 23, 319-329.

Sokal, R.R. \& Rohlf, F.J. (1995) The Principals and Practice of Statistics in Biology Researches, 3rd edn. Freeman W.H., San Francisco, CA.

Stephens, D.W. \& Krebs, J.R. (1986) Foraging Theory. Princeton University Press, Princeton, NJ.

Tenhumberg, B., Keller, M.A., Possingham, H.P. \& Tyre, A.J. (2001) Optimal patch-leaving behaviour: a case study using the parasitoid Cotesia rubecula. Journal of Animal Ecology, 70, 683-691.

Venables, W.N. \& Ripley, B.D. (1994) Modern Applied Statistics with S-Plus. Springer-Verlag, New York.

Vet, L.E.M. \& Bakker, K. (1985) A comparative functional approach to the host detection behaviour of parasitic wasps. II. A quantitative study on eight eucoilid species. Oikos, 44, 487-498.

Vet, L.E.M., Sokolowski, M.B., McDonald, D.E. \& Snellen, H. (1993) Responses of a generalist and a specialist parasitoid (Hymenoptera: Eucoilidae) to drosophilid larval kairomones. Journal of Insect Behavior, 6, 615-624.

Vet, L.E.M. \& van Alphen, J.J.M. (1985) A comparative functional approach to the host detection behaviour of parasitic wasps. I. A qualitative study on Eucoilidae and Alysiinae. Oikos, 44, 478-486.

Vos, M., Hemerik, L. \& Vet, L.E.M. (1998) Patch exploitation by the parasitoids Cotesia rubecula and Cotesia glomerata in multi-patch environments with different host distributions. Journal of Animal Ecology, 67, 774-783.

Waage, J.K. (1978) Arrestment responses of the parasitoid, Nemeritis canescens, to a contact chemical produced by its host, Plodia interpunctella. Physiological Entomology, 3, 135-146.

Waage, J.K. (1979) Foraging for patchily-distributed hosts by the parasitoid, Nemeritis canescens. Journal of Animal Eco$\log y, \mathbf{4 8}, 353-371$.

Wajnberg, E., Fauvergue, X. \& Pons, O. (2000) Patch leaving decision rules and the Marginal Value Theorem: an experimental analysis and a simulation model. Behavioral Ecology, 11, 577-586.

Wajnberg, E. \& Hassan, S.A. (1994) Biology Control with Egg Parasitoids. CAB International, Wallingford, UK.

Wajnberg, E., Rosi, M.C. \& Colazza, S. (1999) Genetic variation in patch time allocation in a parasitic wasp. Journal of Animal Ecology, 68, 121-133.

Wanntorp, H.E. (1983) Historical constraints in the adaptation theory: traits and non-traits. Oikos, 41, 157-160.

Westoby, M., Leishman, M.R. \& Lord, J.M. (1995) On misinterpreting the 'phylogenetic correction'. Journal of Ecology, 83, 531-534.

Received 14 January 2003; revision received 11 March 2003
(C) 2003 British

Ecological Society, Journal of Animal Ecology, 72, 618-626 